\title{
Designing a dual ISM band implantable antenna for medical monitoring applications using Dy- Sm doped magnesium Nano Ferrite material
}

\author{
P.Deepa \\ Asst.Professor/ECE \\ Sethu Inst. Of Tech. \\ Pulloor-626115 \\ Tamil Nadu, India
}

\author{
R. Abdul Sikkandhar \\ Asst.Professor/ECE \\ Sethu Inst. Of Tech. \\ Pulloor-626115 \\ Tamil Nadu, India
}

\author{
Helina Rajini Suresh \\ Professor/ECE \\ Sethu Inst. of Tech., \\ Pulloor - 626115, \\ Tamilnadu, India
}

\author{
Vasant Naidu \\ Professor/ECE \\ Sethu Inst. of Tech., \\ Pulloor - 626115 \\ Tamilnadu, India
}

\begin{abstract}
In this paper we have introduced Dy Sm Ferrite coated on RT DUROID5880 as substrate for an effective constituent to have a patch antenna. Here Dy Sm Ferrite was coated over RT DUROID 5880 with dielectric constant of 1.6 and loss tangent of 0.025 . This combination forms a new substrate for implantable micro strip patch antenna design. The antenna is optimized for dual-band operation by combining an in-house finite-element boundary integral electromagnetic simulation code and particle swarm optimization algorithm. The simulation was performed using IE3D simulator for a frequency range of $2.45 \mathrm{GHz}$ and $5.8 \mathrm{GHz}$ dual ISM Band for medical monitoring applications. The Return loss Was in $2.45 \mathrm{Ghz}-11.99 \mathrm{~dB}$, and $5.8 \mathrm{GHz}-20.37 \mathrm{~dB}$, VSWR values are 1.7266, 2.45Ghz and 1.2415 for $5.8 \mathrm{GHz}$, the Directivity came to be $8.44 \mathrm{dBi}$, these simulated results were encouraging.
\end{abstract}

\section{Key words}

IE3D SIMULATOR, RT Duroid, Nano ferrite materials, Micro strip patch antenna, implantable antenna

\section{INTRODUCTION}

In the recent trends, the ferrites find wide technological applications, as being the high-density materials [1-3]. Synthesis of nanometer size particles proved to be one of the interesting

parts of material science in for various and technological applications. The small size particles have some of the interesting properties as compared to bulk particles, such as improved catalytic, dielectric and magnetic properties, as they possess high resistivity and negligible eddy current Losses [4]. Due to the ever growing demand on dual band antenna and multi function antenna to be utilized in space and military applications, implantable antenna designs have received enormous attention [5]. Quite recently, application of new nano ferrite materials instead of the traditional ferrites has led to the development of low-cost, lightweight antennas that are easily integrated into electrical circuit. [6]Using these nano ferrites, we can actually create micro strip patch (MPA) antenna that will lead to more efficient ways of transmitting and receiving electromagnetic radiations [7] [8] MOST OF THE research on microwave antennas for medical applications has focused on producing hyperthermia for medical treatments and monitoring various physiological parameters. Antennas applied to elevate the temperature of cancer tissues are located inside or outside of the patient's body, and the types of antennas depend on the location. Principal requirements for an antenna are low profile and small size, ability to minimize the radiation absorption MPAs appear to be more suitable for miniaturized applications. We have designed MPA using lanthanide substituted Magnesium ferrite coated over the dielectric substrate ( RT DUROID 5880). As conductivity is one of the material characteristics that determines antenna parameters and eventually performance. are playing dominating in the antenna applications. However the MPA suffer from a number of disadvantages. Narrow bandwidth is a serious limitation of these MPA. Different techniques are used to overcome this narrow bandwidth limitation. These techniques include increasing the thickness of the dielectric substrate, decreasing dielectric constant [7], it was found that the return loss at a frequency range $2.45 \mathrm{GHz}$ was less than $-11.99 \mathrm{~dB}$, and 5.8 Ghz $-20.37 \mathrm{~dB}$ similarly the VSER was 1.7266 for $2.45 \mathrm{Ghz}$ and 5.8Ghz 1.2415 for the substrate[8].In the Design and Optimization of Dual Band Micro Strip Antenna using Practical Swarm Optimization technique for maximizing the return loss for Frequency.

\section{EQUATIONS FOR SIMULATION}

The designed antenna is a 3 _ 3 array. The first step in the design is to specify the dimensions of a single micro strip patch antenna. The patch conductor can be assumed at any shape, but generally simple geometries are used, and this simplies the analysis and performance prediction. Here, the half-wavelength rectangular patch element is chosen as the array element (as commonly used in microstrip antennas) [9]. Its characteristic parameters are the length $\mathrm{L}$, the width $\mathrm{w}$, and the thickness h, as shown in Figure 1. Theoretical analysis and calculations[10] from of all dimensions will be obtained; the essential parameters for the design are:

$\mathrm{F}=2.45 \mathrm{Ghz}$

$\mathrm{H}=1 \mathrm{~mm}$

$\mathrm{Er}=1.6$

2.1Calculation of the Width (W):

The width of the patch element $(\mathrm{W})$ is given by.

$\mathrm{W}=\frac{\mathrm{C}}{2 \mathrm{f}_{0} \sqrt{\frac{\left(\epsilon_{\mathrm{r}}+1\right)}{2}}}$

2.2 Calculation of Effective dielectric constant ( $\left.\varepsilon_{\text {reff }}\right)$ :

The effective of the dielectric constant (creff) depending on the same geometry $(\mathrm{W}, \mathrm{h})$ but is surrounded by a homogeneous dielectric of effective permittivity ereff, whose value is determined by evaluating the capacitance of the fringing field.

$\epsilon_{\text {reff }}=\frac{\epsilon_{\mathrm{r}}+1}{2}+\frac{\epsilon_{\mathrm{r}}-1}{2}\left[1+12 \frac{\mathrm{h}}{\mathrm{w}}\right]^{\frac{1}{2}}$ 


\subsection{Calculation of the Effective length ( eff}

L ):

$\mathrm{L}_{\text {eff }}=\frac{\mathrm{C}}{2 \mathrm{f}_{0 \sqrt{\epsilon_{\text {reff }}}}}$

\subsection{Calculation of the length extension $(\Delta L)$ :}

$$
\Delta \mathrm{L}=0.412 \mathrm{~h} \frac{\left(\epsilon_{\text {reff }}+0.3\right)\left(\frac{\mathrm{W}}{\mathrm{h}}+0.264\right)}{\left(\epsilon_{\mathrm{reff}}-0.258\right)\left(\frac{\mathrm{W}}{\mathrm{h}}+0.8\right)}
$$

\subsection{The actual length $(L)$ of patch}

$\mathrm{L}=\mathrm{L}_{\mathrm{eff}}-2 \Delta \mathrm{L}$

\section{ANTENNA DESCRIPTION}

The results of the nano material coated RT DUROID for the proposed MSPA was simulated using IE3D Simulator with optimization. The software used to model and simulate the microstrip patch antenna is Zeland Inc's IE3D software. IE3D is a full-wave electromagnetic simulator based on the method of moments. It analyzes 3D and multilayer structures of general shapes. It has been widely used in the design of MICs, RFICs, patch antennas, wire antennas, and other RF/wireless antennas. It can be used to calculate and plot the S11 parameters, VSWR, current distributions as well as the radiation patterns.

Table 1: The Proposed antenna has:-

\begin{tabular}{|l|l|l|l|l|l|l|}
\hline $\begin{array}{l}\text { Sl. } \\
\text { no }\end{array}$ & $\begin{array}{l}\text { Patch } \\
\text { length } \\
(\mathrm{mm})\end{array}$ & $\begin{array}{l}\text { Patch } \\
\text { width } \\
(\mathrm{mm})\end{array}$ & $\begin{array}{l}\text { Strip } \\
\text { length } \\
(\mathrm{mm})\end{array}$ & $\begin{array}{l}\text { Strip } \\
\text { width } \\
(\mathrm{mm})\end{array}$ & $\begin{array}{l}\text { Cut } \\
\text { width } \\
(\mathrm{mm})\end{array}$ & $\begin{array}{l}\text { Cut } \\
\text { depth } \\
(\mathrm{mm})\end{array}$ \\
\hline 1. & 47.238 & 69.807 & 12.6711 & 3.7497 & 8.7258 & 8.7258 \\
\hline
\end{tabular}

Table 2 : Optimized result are obtained by the tabulated values

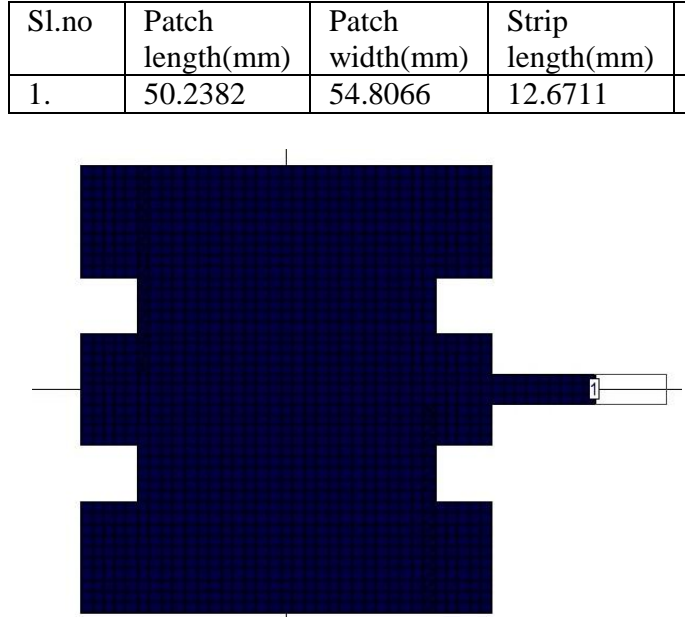

Fig 1: Antenna

\section{RESULT AND DISSCUSSIONS}

Design a dual ism band Micro strip implantable Patch Antenna was designed and a good result was obtained by using optimization in IE3D Simulator for RT DUROID 5880 Substrate. The simulated data's obtained from IE3D were used to plot the graphs.

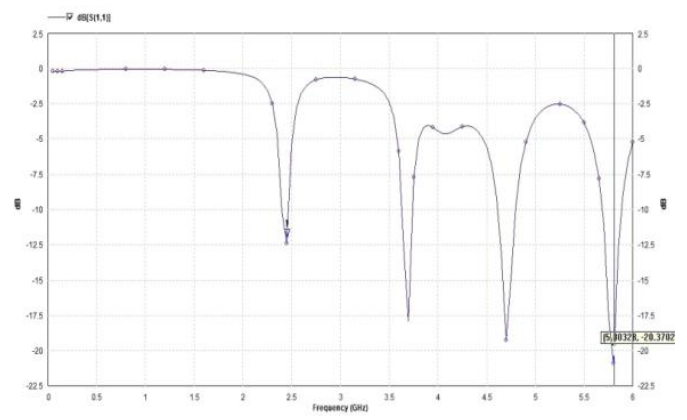

Fig 2: Return loss Vs Frequency (in GHz)

\begin{tabular}{|l|l|l|}
\hline $\begin{array}{l}\text { Strip } \\
\text { width }(\mathrm{mm})\end{array}$ & $\begin{array}{l}\text { Cut } \\
\text { width }(\mathrm{mm})\end{array}$ & $\begin{array}{l}\text { Cut } \\
\text { depth}(\mathrm{mm})\end{array}$ \\
\hline 3.7497 & 8.725834 & 8.725834 \\
\hline
\end{tabular}

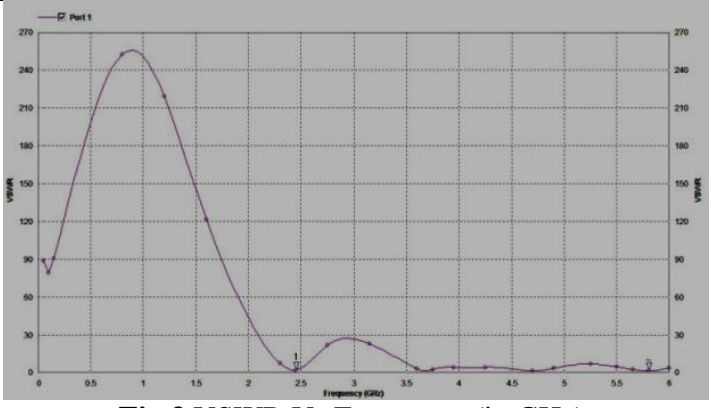

Fig 3 VSWR Vs Frequency (in GHz)

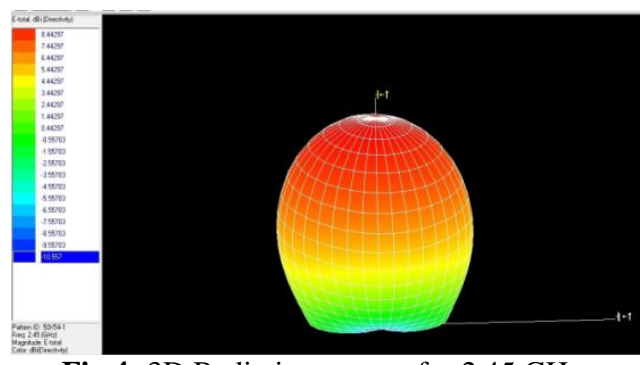

Fig 4: 3D Radiation pattern for $2.45 \mathrm{GHz}$

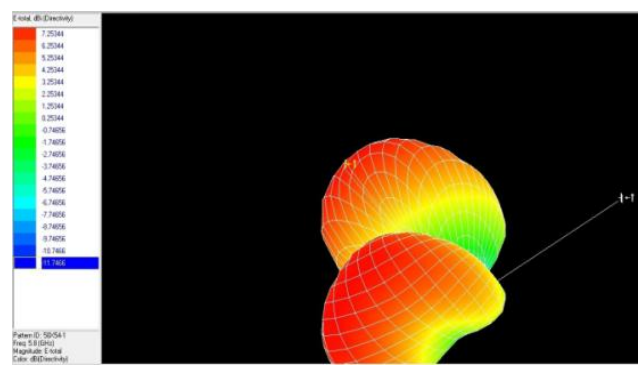

Fig 5: 3D Radiation pattern for $5.8 \mathrm{GHz}$ 
Table 3 : Parametric comparison

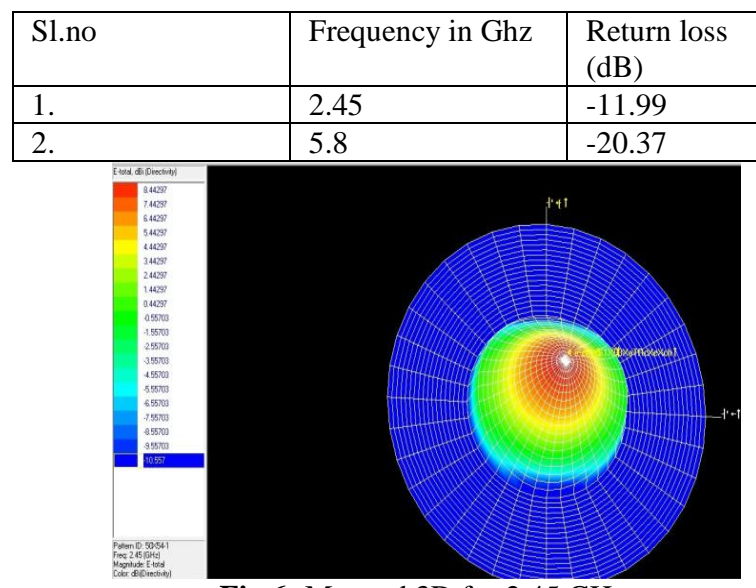

Fig 6: Mapped 3D for $2.45 \mathrm{GHz}$

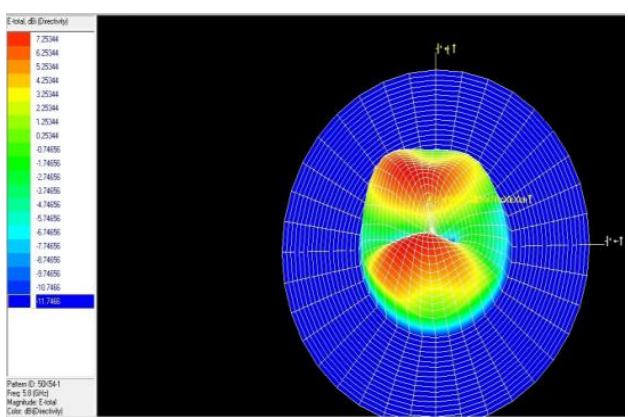

Fig 6: Mapped 3D for 5.8 GHz
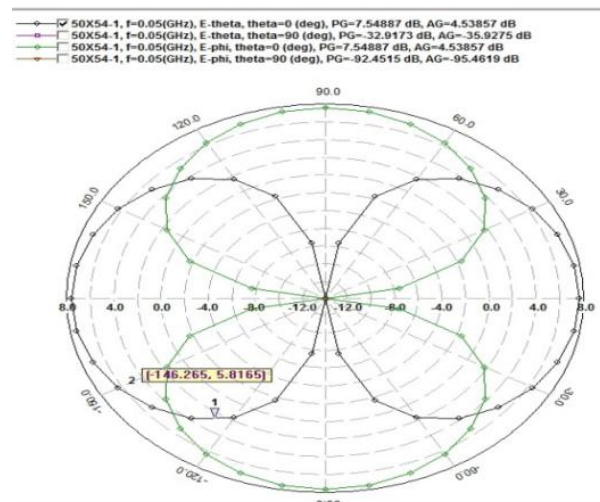

Fig 7: 2D pattern for $2.45 \& 5.8 \mathrm{GHz}$

\begin{tabular}{|l|l|l|}
\hline VSWR & $\begin{array}{l}\text { Directivity } \\
(\mathrm{dbi})\end{array}$ & $\begin{array}{l}\text { Antenna } \\
\text { Efficiency }\end{array}$ \\
\hline 1.7266 & 8.44 & 31.50 \\
\hline 1.2415 & -3.29 & 33.79 \\
\hline
\end{tabular}

$\rightarrow \square s(1,1)$

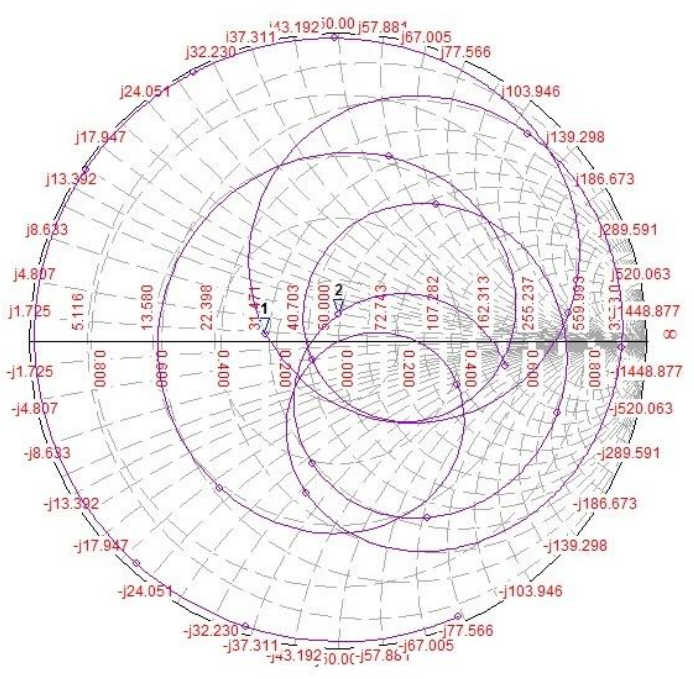

Fig 8: Smith Chart for $2.45 \& 5.8 \mathrm{GHz}$

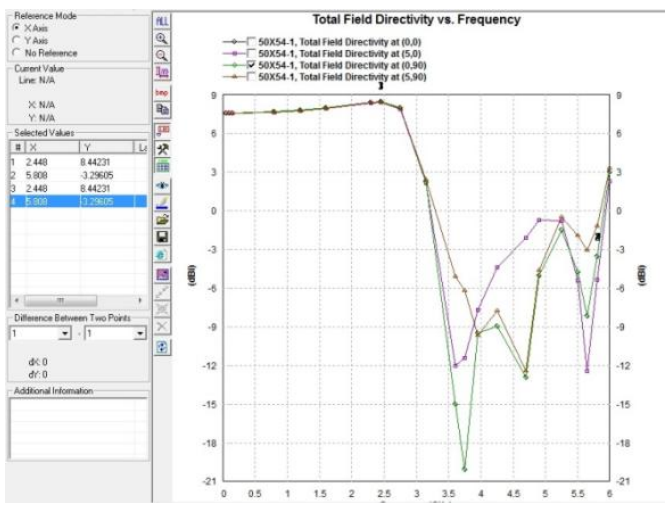

Fig 9: Directivity for $2.45 \& 5.8 \mathrm{GHz}$

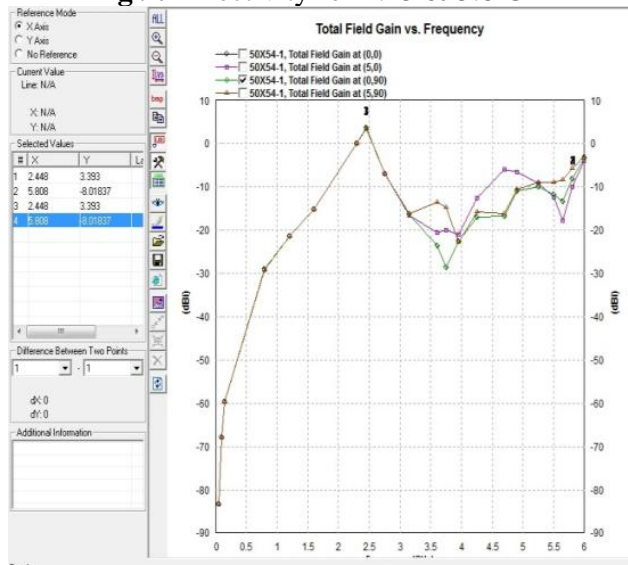

Fig 10: Gain for $2.45 \& 5.8 \mathrm{GHz}$ 

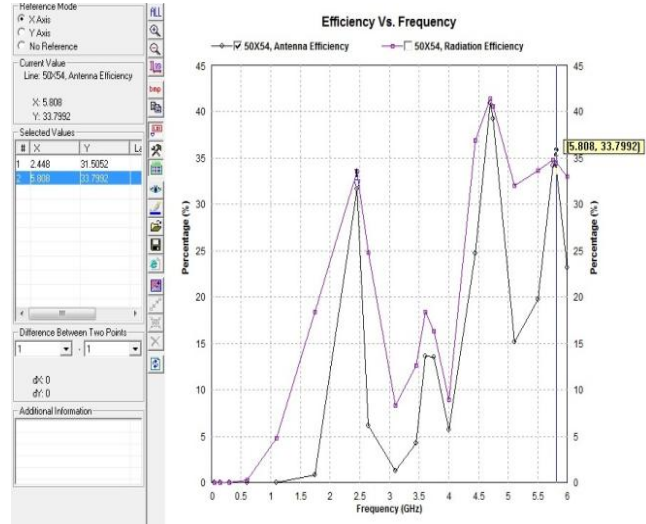

Fig 11: Efficiency for $2.45 \& 5.8 \mathrm{GHz}$

As mentioned in table 1, the data for ISM band frequencies, it is seen that the performance of micro strip implantable patch antenna using DySmxFe2-x O4 material was using for a proposed antenna can be improved by reducing the value of $\varepsilon r$ for the substrate material.

\section{CONCLUSIONS}

Concluding, we introduced the utilization of ferromagnetic compound, namely Dy Smx Fe2-x O4 as a substrate in patch antennas in an effort to tune the radiation characteristics by means of an externally controlled parameter. Especially, in this work we focused on changing and controlling the polarization under the application of an external dc magnetic field. If the concentration of $\mathrm{Sm}$ is increased to higher percentage. The expected result will be further encouraging and this implantable antenna will be applicable to a dual ism band for medical monitoring applications.

\section{ACKNOWLEDGMENT}

This work was partly funded under DRDO project, No.ERIP/ER/0704407/M/01.

\section{REFERENCES}

[1] M A Jacob.John, Khadar, Lonappan.Anil and K.T Mathew, Microwave dielectric properties of nano structured nickel ferrite, Bull, Mater. Sci,31- 6.(2008) pp. 847-851.

[2] Vasant Naidu, S.K.A. Ahamed KanduSahib, M.SheikDawood, M.Suganthi; Magnetic Properties of Nano Crystalline Nickel, Samariumdoped Zinc Ferrite ,International Journal of Computer Applications,242,(June 2011),pp. $0975-8887$.

$$
\text { Vasant Naidu, }
$$

S.K.A.Ahamed KanduSahib,M.SheikDawood, M.Suganthi; Magnetic Properties of Nano Crystalline Nickel, Cerium doped Zinc Ferrite, International Journal of Nano tech and Nano Sci in press.
[4]Vasant Naidu et.al "Mg Sm Ferrite for Nano structured EShaped Patch Antenna studies" Int. J.Com.Appl, Volume 30-No.5,pp 45-50, Sept 2011.

[5] A.T Raghavendera., Damir Pajic, kreso Zadro,Tomislav Milekovic, Venkateshwar Rao.P. Jadhav K M and Ravinder D,Synthesis and Magnetic properties of NiFe2xAlxO4 nano particles, Mag J and Mag Mat, 1 (2007). Pp 316.

[6] Burke P.J, S.Li and Z. Yu, Quantitative theory of nanowire and nanotube antenna performance Nanotechnology, IEEE transactions on, 2006, 5(4); p314-334.

[7] Demoustier, S., et al., Review of two microwave applications of carbon nanotubes: nano-antennas and nano-switches. Comptes Rendus Physique, 2008. 9(1): p.53-66.

[8] Ahmed H. Reja "Study of Micro Strip Feed Line Patch Antenna", Antennas and Propagation International Symposium, vol. 27, pp. 340-342 December 2008.

[9] Sahntanu Kumar Behera and Y. Choukiker, "Design and Optimization of Dual Band Micro Strip Antenna Using Practicle Swarm Optimization Technique," in Springer Science+Business Media, LLC, pp. 1346-1354, 2010.

[10] A. A. Deshmukh and G. Kumar, "Compact broadband gap-coupled shorted L-shaped microstrip antennas," in IEEE Antennas and Propagation International Symposium, vol 1, (Baltimore, Maryland), pp. 106-109, IEEE, July 2001.

[11] Z. M.Chen and Y.W.M. Chial, "Broadband probe-fed Lshaped plate antenna," Microwave and Optical Technology Letters, vol. 26, pp. 204-206, 1985.

[12] D. Wessels, "Implantable pacemakers and defibrillators: Device overview and EMI considerations," in IEEE Electromagnetic Compatibility Int. Symp., vol. 2, 2002, pp. 911-915.

[13] J. Kim and Y. Rahmat-Samii, "An implantable antenna in the spherical human head: SAR and communication link performance," presented at the IEEE Topical Wireless Communication Technology Conf., Oct 2003.

[14]W. Xia, K. Saito, M. Takahashi, and K. Ito, "Performances of an implanted cavity slot antenna embedded in the human arm," IEEE Trans.Antennas Propag., vol. 57, pp. 894-899, Apr. 2009. 